\title{
Surgical site infection prevention bundle for children submitted to cardiac surgery
}

\author{
Bundle de prevenção de infecção de sítio cirúrgico em crianças submetidas à cirurgia cardíaca \\ Bundle para la prevención de la infección de sitio quirúrgico en los niños sometidos a \\ cirugía cardíaca
}

How to cite this article:

Andrade GV, Souza NMG, Rocha ACF, Ribeiro SB, Silva VM, Oliveira LAF. Surgical site infection prevention bundle for children submitted to cardiac surgery. Rev Esc Enferm USP. 2021;55:e20200470. doi: https://doi.org/10.1590/1980-220X-REEUSP-2020-0470

\author{
Giselle Viana de Andrade ${ }^{1}$ \\ Nayana Maria Gomes de Souza ${ }^{2}$ \\ Ana Caroline Felisola Rocha ${ }^{1}$ \\ Silvania Braga Ribeiro ${ }^{1}$ \\ (D) Viviane Martins da Silva ${ }^{2}$ \\ D Luis Adriano Freitas Oliveira ${ }^{3}$ \\ ${ }^{1}$ Hospital de Messejana Dr. Carlos Alberto \\ Studart Gomes, Fortaleza, CE, Brazil. \\ ${ }^{2}$ Universidade Federal do Ceará, Programa \\ de Pós-Graduação em Enfermagem, \\ Fortaleza, CE, Brazil. \\ ${ }^{3}$ Faculdade Terra Nordeste, Fortaleza, CE, Brazil.
}

\begin{abstract}
Objective: To build and validate the content and appearance of a surgical site infection prevention bundle for children submitted to cardiac surgery. Method: Methodological study in two phases: 1) Bundle construction from an integrative literature review from which interventions have been extracted to compose the instrument; 2) Bundle content and appearance validation by 24 judges. Results: The 24 found articles presented 17 interventions for surgical site infection prevention in this population. Out of them, seven intervention proposals have been chosen to compose the bundle and sent for assessment by judges. The final proposal includes all the seven items chosen in the construction phase and has achieved a content validity index over 0.8 in all items referring to content and appearance. Conclusion: The content and appearance of the developed bundle proposes care for the prevention of surgical site infection throughout the perioperative period.
\end{abstract}

\section{DESCRIPTORS}

Thoracic Surgery; Child; Sugery Wound Infection; Perioperative Nursing; Validation Study.
Corresponding author:

Nayana Maria Gomes de Souza

Rua Alexandre Baraúna, 1115, Rodolfo Teófilo

60020-181 - Fortaleza, CE, Brazil

nayanamgs@hotmail.com
Received: 11/02/2020

Approved: 04/22/2021 


\section{INTRODUCTION}

Surgical Site Infections (SSI) are those which affect incised tissues and organs and cavities which are manipulated during a surgical procedure, taking place in the first 30 days from the operation or within a year. Despite improvements in surgical techniques and infection control practices, the SSI correspond to 14 to $16 \%$ of all Healthcare Associated Infections (HAIs) in Brazil ${ }^{(1)}$.

In pediatric cardiac surgery, the incidence of this kind of infection ranges from $0.25 \%$ to $6 \%{ }^{(2)}$, in addition to increasing mortality rates by $2.5^{(3)}$, elevating hospital costs, and prolonging hospitalization, leading to potential damage to the health of individuals which are affected by this complication ${ }^{(2)}$.

The main risk factors for the development of SSI in children submitted to cardiac surgery include being younger than one month, prolonged use of mechanical ventilation, hospitalization in Intensive Care Unit (ICU) in the preoperative period, prolonged use of invasive devices in the post-operative period, and complex heart disease $^{(2,4)}$. Therefore, SSI prevention is a challenge for health professionals who deal with this population due to their immunological immaturity, as well as anatomical and physiological characteristics of heart diseases that contribute to poor prognosis, in addition to the fact that the dynamics of perioperative procedures for this type of surgery are complex.

In face of this, the risks for children submitted to cardiac surgeries are a present reality in surgical care and teams involved in this process are responsible for proposing strategies and establishing barriers for guaranteeing patient safety. Therefore, to guarantee the continuous improvement of quality of care and patient safety, the implementation of bundles, or care packages, has been adopted as a strategy to minimize SSI, since it reduces the variability of care procedures $^{(5-7)}$.

Bundles are "packages" of specific care procedures that, when implemented collectively, improve healthcare results $^{(8-9)}$. It is a light-hard technology proposed by the Institute for Healthcare Improvement ${ }^{(10)}$, whose construction is based on the best evidence for health practice ${ }^{(10)}$ with the objective of reducing adverse events related to health care $^{(8,11-13)}$.

Scientific evidence points out that the selection of care procedures to be included in bundles must consider cost-benefit, easiness of implementation, and adherence of health teams to these care "packages" (8,9). Also, favorable results in the use of bundles require all interventions to be executed jointly, with no exclusion of any phase $\mathrm{e}^{(8-9,12)}$.

Therefore, the construction and validation of a bundle for SSI prevention may help the development of safer and more efficient practices concerning the maintenance of surgical site integrity of children submitted to cardiac surgery. In this context, the objective of this study is to construct and validate the content and appearance of a surgical site infection prevention bundle for children submitted to cardiac surgery. It is also emphasized that there is no evidence in the Brazilian literature regarding the use of bundles for SSI prevention in any population.

\section{METHOD}

\section{Design of Study}

This is a methodological study guided by the SPIRIT tool ${ }^{(14)}$, performed in two phases: 1) Construction of a SSI prevention bundle based on an integrative literature review, from which interventions have been extracted to compose the instrument; 2) Bundle content and appearance validation. The data collection period lasted from September to November 2019.

\section{Data Collection}

\section{Phase 1 - CONStruction OF the SSI PReVention BUNDLE}

Initially, an integrative literature review was performed with data extracted from three databases (PUBMED, CINAHL, Web of Science) with the descriptors "surgical wound", "thoracic surgery" and "child" associated to one another by the Boolean operator "AND". The review had the following guiding question: which interventions are performed for the prevention of operative wound infection in children submitted to cardiac surgeries?

The inclusion criteria for articles in this phase were original articles whose results presented interventions for the prevention of operative surgical wound infection in children submitted to cardiac surgery and with abstracts available in the databases. The exclusion criteria were documents presented in congresses, dissertations, monographs, theses, letters to editors, and reflection studies.

To ensure this phase's quality and to avoid selection biases, all studies have been checked by two reviewers independently. Inclusion or non-inclusion of studies was assessed based on reading the title and abstract. In case of disagreement between the two reviewers, a third reviewer was involved. The articles which were initially unavailable in databases were obtained in full text on the website of Coordination for The Improvement of Higher Education Personnel (Coordenação de Aperfeiçoamento de Pessoal de Nivel Superior-CAPES). The selected articles have been assessed through full text reading so as to ensure that the inclusion criteria were met.

The following filters were used for search: publications available in full text between 2010 and 2019 in English, Portuguese, and Spanish. The initial sample was composed of 2,549 publications extracted from PUBMED, 549 from Web of Science, and 25 from CINAHL. After reading titles and abstracts, the sample was reduced to 18,33 and 10, respectively. Finally, 24 articles were selected for complete reading: 07 from PUBMED, 07 from Web of Science, and 10 from CINAHL.

Data extraction from the selected articles was performed using an instrument containing descriptive variables of the publications, complementing data such as authorship, 
year of publication, journal, database, evidence level, and the identification of interventions for surgical site infection prevention in children submitted to cardiac surgery, in addition to the description of the efficacy of employed interventions.

After the review a group of physicians and nurses at the pediatric cardiology service of Messejana Dr. Carlos Alberto Studart Gomes Hospital analyzed each intervention identified in the data extraction phase searching for a consensus on which interventions would comprise the bundle. Finally, the interventions which would comprise the surgical site infection prevention bundle were chosen.

Subsequently a textual media or hypertext was built using Microsoft Power Point version 2010, a program which is broadly used in business and personal computers and is contained in Microsoft Office 2010, available for Windows. All elements of this hypertext are emphasized to have been produced by the study's authors assisted by an informatics professional.

\section{PhASE 2 - SSI PREVENTION BUNDLE CONTENT AND APPEARANCE VALIDATION}

After component identification and the creation of a hypertext for the surgical site infection prevention bundle for children submitted to cardiac surgery, in the following phase, content and appearance was validated, so as to verify with the judges whether the developed bundle effectively explored surgical site infection prevention.

An adaptation of instruments used in similar studies ${ }^{(15-16)}$ was employed. It was divided into three parts: the first part was composed of judges' characterization, the second part was related to the content of the interventions chosen for this bundle, identified in the literature review, and finally, the third part contained information regarding the presentation and structure of the developed hypertext.

Concerning the content of the interventions, the judges assessed the relevance, objectivity, simplicity, clarity, and accuracy of each intervention in the SSI prevention bundle. Relevance refers to the capacity of the item of being consistent with the defined attribute, objectivity enable the item to be brief regarding the definite attribute, simplicity is expressing a single idea, and clarity enabled defining whether the measure was intelligible, with simple and unambiguous expressions, and finally, accuracy enabled regularity in execution ${ }^{(15)}$.

In addition to content validation, the judges analyzed the structure, presentation, and usability of the developed hypertext. Issues related to structure and presentation verified bundle intervention presentation through questions which are pertinent to overall organization, structure, presentation strategy, and formatting. The items related to usability assessed whether the form of presentation of the hypertext was considered easy to use and learn, providing clear, complete, concise, and fast assistance ${ }^{(16)}$.

For bundle content and appearance analysis by the judges, the answers followed a Likert-type scale with four support levels: 1 (completely disagree), 2 (partially disagree), 3 (partially agree), and 4 (completely agree). This process was conducted through the Delphi technique and the judges were informed that, in case of negative answers, the components would be changed and/or excluded in accordance with the suggestions.

\section{SAMPle Definition}

The inclusion criteria for this phase were physicians and nurses with the title of specialist and/or Master and/or $\mathrm{PhD}$ and a minimum two-year experience in post-operative pediatric cardiac surgery. The judges were selected through their curriculum on the Lattes Platform in the National Council for Scientific and Technological Development (CNPq - Conselho Nacional de Desenvolvimento Cientifico e Tecnológico) website and the adopted sampling strategy was snowball. An invitation letter, which provided information on this research, was sent through electronic mail. Upon confirmation of this invitation, the judges received the ICF and the research questionnaire. Out of the 30 selected judges, only 24 accepted to participate in the study and sent a filled data collection instrument.

\section{Data Treatment and Analysis}

The data were organized in a spreadsheet available in the Microsoft Office Excel 2016 program and analyzed through the statistical program $\mathrm{R}$ version 3.2.0. The characterization by the judges was based on descriptive analysis, which included absolute frequencies and percentages. The identification of adherence to normal distribution was performed through application of the Shapiro-Wilk test.

The Content Validity Index (CVI) was calculated for content and appearance validity analysis of the interventions chosen for the surgical site infection prevention bundle for children submitted to cardiac surgery. Using the weighted median as an estimate for CVI was opted for due to the identification of non-normality in estimate distribution. In addition to the CVI median estimate, 95\% confidence interval and interquartile interval for each median were calculated with CVI higher than or equal to 0.8 as a reference value for null hypothesis. An item was thus considered valid for the developed bundle if the CVI was statistically equal to or higher than 0.8 .

\section{Ethical Aspects}

Meeting the ethical aspects of scientific research this study was submitted to and approved by the Research Ethics Committee of Messejana Dr. Carlos Alberto Studart Gomes Hospital on August 7, 2018, opinion n. 2.803.710, in accordance with the recommendations of resolution 466, dated December 12, 2012, by the National Health Council.

\section{RESULTS}

The 24 articles which have been found presented 17 interventions for preventing surgical site infection in this population. Out of a total of 17 identified interventions, 10 interventions were excluded by the consensus group for the elaboration of this bundle: 1 . Use of individual electric device for preoperative hair removal, 2 . use of $2 \%$ mupirocin nasal ointment twice a day for five days before surgical 
procedure, 3. daily review of air conditioner filter of the surgical room, 4. use of intravenous corticoid before the start of extracorporeal circulation, 5. transthoracic echocardiogram with post-surgery sterile protection, 6 . use of nylon bandage impregnated with silver on the surgical wound, 7. sternotomy on the bed of a pediatric intensive care unit (PICU) in cases in which the sternum remained open after cardiac surgery, 8. daily body hygiene with chlorexidine germicidal solution after surgical procedure, 9. cleaning the stethoscope and electrocardiogram cables with sterile disinfectant wipes, 10. mediastinal control cultures every seven days for 30 days after surgery.

All the interventions mentioned in the previous paragraph were excluded due to the impossibility of their application to the reality of Brazilian hospital service, in addition to not having enough description of intervention efficacy, which precluded understanding the developed actions of these prevention strategies.

Finally, seven interventions were chosen to compose the surgical site infection prevention bundle and, subsequently, a hypertext with the content organized into a temporal sequence of three operative periods (Figure 1) was produced. Throughout the process of developing this tool, providing an attractive and understandable text, using texts, images, flowcharts, and different colors to distinguish the interventions performed in each operative period was aimed at, with the objective of easily identifying the care procedures chosen for SSI prevention.

The interventions are emphasized to have been divided into three operative periods (preoperative, intraoperative and postoperative) with the objective of guaranteeing adherence to good care practices for children submitted to cardiac surgery throughout perioperative period, thus leading to a better clinical outcome than they do when individually implemented.

The selection of interventions to compose this bundle was guided by evidence which proved its efficacy and usefulness. Thus, interventions 1, 2, 3, 6 and 7 derive from evidence of well-designed non-randomized clinical trials (evidence level III) and well-designed case-control and cohort studies (evidence level IV), and intervention 4 derives only from studies with evidence level III and intervention 5 is derived from evidence from well-designed randomized clinical trials (evidence level II).

To validate content and appearance, the instrument was submitted to a sample composed of 30 judges. The return rate of the instruments was $80 \%$. Out of the judges who composed the final sample, 18 were nurses and six were physicians with clinical practice experience in the post-operative pediatric cardiac surgery.

\section{SURGICAL SITE INFECTION PREVENTION BUNDLE}

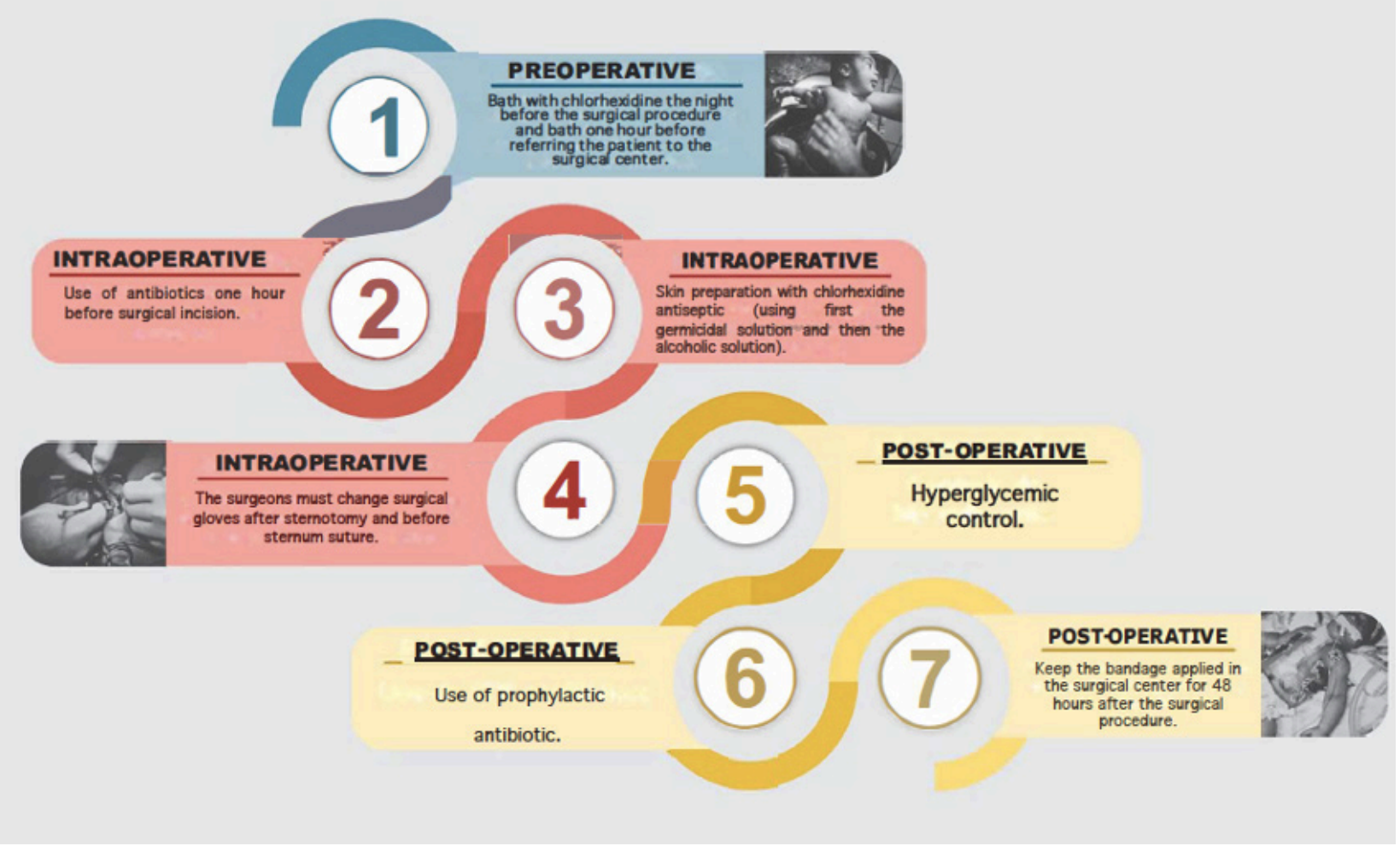

Figure 1 - Hypertext of the surgical site infection prevention bundle - Fortaleza, CE, Brazil, 2020. 
The sample of judges was characterized by participants aged 32 to 57 , with a median of 43.5 years (IQI \pm 14 ). Concerning time of professional education, participants had a mean of 18.67 years $(\mathrm{SD} \pm 8.92)$. Their median of experience with care in postoperative pediatric cardiac surgery was 13 years (IQI \pm 09$)$. Most were female $(70.8 \%)$, with a specialist title $(66.6 \%)$, and from the city of Fortaleza, Brazil (91.7\%), and Seattle, United States (8.3\%). Current profession was verified to be care practice nurse for $62.5 \%$ of the sample and the other $37.5 \%$ were coordinating nurses, coordinating physicians, or care-providing physicians.

The data presented in Table 1 show the judgment by the judges regarding content analysis of each intervention chosen for the SSI prevention bundle.

According to the data presented in Table 1, all seven items presented CVI $>0.8$ with statistically significant values for relevance, objectivity, simplicity, clarity, and accuracy. All interventions have thus been included in the final list.

Table 1 - Judges' analysis of the content of the SSI prevention bundle for children submitted to cardiac surgery - Fortaleza, CE, Brazil, 2020.

\begin{tabular}{|c|c|c|c|c|c|}
\hline $\begin{array}{l}\text { Variables } \\
\text { 1. Bath with chlorhexidine the night before the surgical procedure and bath one hour before } \\
\text { referring the patient to the surgical center }\end{array}$ & p-value* & CVI & IQI & \multicolumn{2}{|c|}{$95 \% \mathrm{Cl}$} \\
\hline Relevance & - & 1.00 & - & - & - \\
\hline Objectivity & - & 1.00 & - & - & - \\
\hline Simplicity & $<0.001$ & 1.00 & 0 & 0.75 & 1.00 \\
\hline Clarity & $<0.001$ & 1.00 & 0 & 0.75 & 1.00 \\
\hline Accuracy & $<0.001$ & 1.00 & 0 & 0.75 & 1.00 \\
\hline \multicolumn{6}{|l|}{ 2. Use of antibiotics one hour before surgical incision } \\
\hline Relevance & - & 1.00 & - & - & - \\
\hline Objectivity & $<0.001$ & 1.00 & 0 & 0.75 & 1.00 \\
\hline Simplicity & $<0.001$ & 1.00 & 0 & 0.75 & 1.00 \\
\hline Clarity & $<0.001$ & 1.00 & 0 & 0.75 & 1.00 \\
\hline Accuracy & $<0.001$ & 1.00 & 0 & 0.75 & 1.00 \\
\hline \multicolumn{6}{|l|}{ 3. Skin preparation with chlorhexidine antiseptic } \\
\hline Relevance & - & 1.00 & - & - & - \\
\hline Objectivity & $<0.001$ & 1.00 & 0 & 0.75 & 1.00 \\
\hline Simplicity & $<0.001$ & 1.00 & 0 & 0.75 & 1.00 \\
\hline Clarity & $<0.001$ & 1.00 & 0 & 0.75 & 1.00 \\
\hline Accuracy & $<0.001$ & 1.00 & 0 & 0.75 & 1.00 \\
\hline \multicolumn{6}{|c|}{ 4. The surgeons must change surgical gloves after sternotomy and before sternum suture } \\
\hline Relevance & $<0.001$ & 1.00 & 0 & 0.75 & 1.00 \\
\hline Objectivity & $<0.001$ & 1.00 & 0 & 0.75 & 1.00 \\
\hline Simplicity & $<0.001$ & 1.00 & 0 & 0.75 & 1.00 \\
\hline Clarity & $<0.001$ & 1.00 & 0 & 0.75 & 1.00 \\
\hline Accuracy & $<0.001$ & 1.00 & 0 & 0.75 & 1.00 \\
\hline \multicolumn{6}{|l|}{ 5. Hyperglycemic control } \\
\hline Relevance & $<0.001$ & 1.00 & 0 & 0.75 & 1.00 \\
\hline Objectivity & $<0.001$ & 1.00 & 0 & 0.75 & 1.00 \\
\hline Simplicity & $<0.001$ & 1.00 & 0 & 0.75 & 1.00 \\
\hline Clarity & $<0.001$ & 1.00 & 0 & 0.75 & 1.00 \\
\hline Accuracy & $<0.001$ & 1.00 & 0 & 0.75 & 1.00 \\
\hline \multicolumn{6}{|l|}{ 6. Use of prophylactic antibiotic } \\
\hline Relevance & - & 1.00 & & - & - \\
\hline Objectivity & $<0.001$ & 1.00 & 0 & 0.75 & 1.00 \\
\hline Simplicity & $<0.001$ & 1.00 & 0 & 0.75 & 1.00 \\
\hline Clarity & $<0.001$ & 1.00 & 0 & 0.75 & 1.00 \\
\hline Accuracy & - & 1.00 & & - & - \\
\hline \multicolumn{6}{|c|}{ 7. Keep the bandage applied in the surgical center for 48 hours after the surgical procedure } \\
\hline Relevance & $<0.001$ & 1.00 & 0 & 0.75 & 1.00 \\
\hline Objectivity & $<0.001$ & 1.00 & 0 & 0.75 & 1.00 \\
\hline Simplicity & $<0.001$ & 1.00 & 0 & 0.75 & 1.00 \\
\hline Clarity & $<0.001$ & 1.00 & 0 & 0.75 & 1.00 \\
\hline Accuracy & $<0.001$ & 1.00 & 0 & 0.75 & 1.00 \\
\hline
\end{tabular}

- values presenting no variability; CVI - content validity index; IQI - interquartile interval; $95 \% \mathrm{CI}$ - $95 \%$ confidence interval. 
Table 2 - Judges' analysis of the appearance of the SSI prevention bundle for children submitted to cardiac surgery - Fortaleza, CE, Brazil, 2020.

\begin{tabular}{|c|c|c|c|c|c|}
\hline Variables & p-value* & CVI & IQI & \multicolumn{2}{|c|}{$95 \% \mathrm{Cl}$} \\
\hline 1. Presents the logical sequence of the proposed content. & $<0.001$ & 1.00 & 0 & 0.75 & 1.00 \\
\hline 2. The information is well-structured concerning agreement and orthography. & $<0.001$ & 1.00 & 0 & 0.75 & 1.00 \\
\hline 3. Font size and type are appropriate to reading. & $<0.001$ & 1.00 & 0 & 0.75 & 1.00 \\
\hline 4. The colors applied to the text and the chart are appropriate. & $<0.001$ & 1.00 & 0 & 0.75 & 1.00 \\
\hline 5. The visual composition is attractive and well-organized. & $<0.001$ & 1.00 & 0 & 0.75 & 1.00 \\
\hline \multicolumn{6}{|l|}{ Usability } \\
\hline 6. The bundle items portray key aspects which should be reinforced. & $<0.001$ & 1.00 & 0 & 0.75 & 1.00 \\
\hline $\begin{array}{l}\text { 7. It is appropriate for use by health professionals when providing care to children } \\
\text { submitted to cardiac surgery. }\end{array}$ & $<0.001$ & 1.00 & 0 & 0.75 & 1.00 \\
\hline
\end{tabular}

CVI - content validity index; IQI - Interquartile interval; $95 \% \mathrm{CI}-95 \%$ confidence interval.

It should be emphasized that there were suggestions from the judges for some items whose presentation form required revision, more clarity and accuracy. The bundles were adjusted as follows: intervention 1 was initially forwarded to the judges as "Bath with chlorhexidine the night before the surgical procedure, and a bath one hour before surgery" and the vocabulary was thus rearranged so as not to cause ambiguity and the phrase "before forwarding the patient to the surgical center" was added to the end of the sentence; for intervention 3, the judges asked for the order of use of the antiseptic chlorhexidine solutions to be "using first the germicidal solution and then the alcoholic solution"; finally, the last suggestion was adding to intervention 4 who would perform the change of surgical glove.

Table 2 presents the CVIs obtained among judges for the appearance of the hypertext of the surgical site infection prevention bundle. As in content validation, all the statements related to validation of the produced hypertext appearance presented $\mathrm{CVI}>0.8$, constituting an appropriate instrument, according to the judges' opinions, for the prevention of surgical site infection in children submitted to cardiac surgery.

\section{DISCUSSION}

The bundle strategy methodology presupposes that joint application of interventions is proven to be more efficient than the application of isolated measures ${ }^{(11,13)}$. Adherence to bundle use has been thus presenting significant results for the reduction of SSI in children submitted to cardiac surgery, concomitantly to permanent education activities ${ }^{(5-7)}$. In this context, as in international organizations, the Brazilian Health Regulatory Agency (Anvisa - Agência Nacional de Vigilância Sanitária) has been recommending the adoption of bundles for SSI prevention, given its impact on care and reduction of infection rates, presupposing that the choice of these interventions considers cost, easiness of implementation, and adherence ${ }^{(1)}$.

The literature review has shown interventions which were not included in the bundle version submitted to judge appreciation. The interventions use of individual electric device for preoperative hair removal, daily review of air conditioner filter of the surgical room, transthoracic echocardiogram with sterile protection after surgery, use of nylon bandage impregnated with silver on the operative wound, cleaning stethoscope and electrocardiogram cable with sterile disinfectant wipes and mediastinal control cultures every seven days for 30 days after surgery were excluded by the consensus group for bundle elaboration due to their high cost, in addition to the lack of sufficient description of intervention efficacy ${ }^{(5-7,17)}$.

The primary studies employing the interventions use of $2 \%$ mupirocin nasal ointment twice a day for five days before surgical procedure and the use of intravenous corticoid before the start of extracorporeal circulation showed no statistically significant difference in the reduction of operative wound infection rate $^{(5-7)}$; therefore, these items were not selected to comprise the bundle. The decision process for the exclusion of the sternotomy intervention on the bed of pediatric intensive care unit (PICU) in cases in which the sternum remained open after cardiac surgery was due to the impossibility of its application to the reality of the public hospital service in which the consensus group for the elaboration of the bundle was employed, where physical space between PICU beds are separated by a 6 meter distance for each bed and not by four walls and an entrance door, as in the primary studies which have been extracted ${ }^{(5,7)}$, precluding the mobility restrictions within the PICU and the necessary sterile conditions to proper surgery conduction.

The intervention daily body hygiene with chlorhexidine germicidal solution after surgery was due the contraindication of routine use of chlorhexidine germicidal solution in newborns due to their skin immaturity, which predisposed to lesions if used daily ${ }^{(1)}$. Thus, with the objective of unifying the interventions for the whole pediatric group submitted to cardiac surgery, including newborns, infants, children, and adolescents, this intervention was removed from the bundle.

The interventions chosen and validated by the judges to compose the bundle for SSI prevention in children submitted to cardiac surgery are subsequently discussed based on the literature.

The first bundle item was "Bath with chlorhexidine the night before the surgical procedure and bath one hour before referring the patient to the surgical center" in the pre-operative period. The main objective of the preoperative bath is to reduce the microbial load in patient skin microbiota. Some 
microorganisms can be removed through common bath using water and soap, but microorganisms which are more resistant to antibiotics require a more robust and efficient removal method that uses chemical processes (antiseptic skin solution which destroys microorganisms and prevents rebound colonization) and mechanical processes (application of antiseptic skin solution with appropriate attrition to guarantee that all cracks and fissures be sufficiently covered by the solution $)^{(18)}$.

A clear association between preoperative bath with antiseptic product germicidal chlorhexidine and the reduction of SSI risk has not been demonstrated yet ${ }^{(1,17,19)}$; however, due to the fact that chlorhexidine has a persistent action, i.e., it grants antiseptic properties for some time after application when compared to other antiseptic agents ${ }^{(19)}$, bath with germicidal chlorhexidine the night before and one hour before surgical procedure was chosen to compose the bundle, ensuring the reduction of microorganisms in the children's skin.

The next three items under discussion refer to the intraoperative period. Item two includes the use of antibiotic one hour before surgical incision. The efficacy of prophylaxis with antibiotic administered one hour before surgical incision for the prevention of surgical infections is firmly proven for the adult population. However, for the pediatric population, there are few studies on the efficacy of this intervention for SSI prevention ${ }^{(20)}$.

A study performed in Michigan, United States, reported that children submitted to cardiac surgery for whom antibiotics had been administered over one hour before surgical incision and/or after surgical incision had a risk 1.7 times higher of SSI when compared to children who had received antibiotics in the recommended period, i.e., one hour before surgical incision ${ }^{(20)}$. Although only one evidence corroborates the efficiency of this intervention for SSI prevention in children submitted to cardiac surgery, it was included in the bundle due to being a viable intervention for application in clinical practice and having a higher cost-benefit when compared to the established SSI treatment.

The antimicrobial used as prophylaxis for children submitted to cardiac surgery is emphasized to be varied; however, cephalosporins are among the most used and recommended for this population due to its broad spectrum of action against gram-negative and gram-positive bacteria ${ }^{(5-7)}$.

Item 3 contemplates skin preparation with chlorhexidine antiseptic when the child is placed in the operating table, first using germicidal solution and right after the alcoholic solution. The objective of this intervention is to avoid the re-introduction of microorganisms into the surgical site, in addition to guaranteeing that it is free of debris and fat, reducing thus the risk of developing $\mathrm{SSI}^{(18,21)}$. The use of antiseptic germicidal and alcoholic solution for skin preparation is emphasized to include circularly cleaning the incision site skin towards the periphery, requiring the two types of antiseptic solution to be left to dry in the patient's skin before a new procedure is started. Also, it must be performed with sterile gloves and no sterile apron, given that the risk of apron contamination is high ${ }^{(18)}$.
Similarly to the preoperative bath (intervention 1 ), the antiseptic chlorhexidine solution was chosen due to its broad spectrum, i.e., significant reduction of microorganisms, not causing irritation during the surgical procedure, and having a persistent effect, i.e., suppressing the growth of microorganisms up to six hours, in addition to having weaker associations with surgical site infection rates when compared to other antiseptic solutions ${ }^{(21)}$. In face of this, this intervention was eligible and validated by the judges to comprise the bundle with the intention of reducing as much as possible the microbial load in the patient's skin before skin barrier incision, consequently preventing SSI.

The fourth item is related to change of surgical glove after sternotomy and before sternum suture by surgeons: "The sterile surgical gloves are used complementary to hand surgical antisepsis and provide a physical barrier to patient contamination with the microorganisms in the hands of health professionals"(22). "However, their use is susceptible to flaws, and the occurrence of (micro) perforations/tears that compromise the capacity of patient protection due to exposure to piercing and cutting material, bone fragments, and chemical products is common, an event which may double the risk of SSI"(22).

Thus, "to minimize damage due to the presence of microorganisms in the operative wound from the hands of the surgical team" ${ }^{(22)}$, the change of surgical glove after sternotomy and before sternum suture in children submitted to cardiac surgery ${ }^{(5)}$ was selected to comprise the SSI prevention bundle.

The items five, six, and seven refer to the post-operative period. Item five refers to hyperglycemia control. Children submitted to cardiac surgery undergo highly stressful situations, such as surgical incisions, vasoactive drug infusion, deep hypothermia, cardiac arrest, and extracorporeal circulation, which may lead to an increase in gluconeogenesis and glycogenolisis, resulting in high serum glucose levels, so as to guarantee an appropriate substrate to maintain the skeletal muscle and the brain functions, which are essential for survival ${ }^{(23)}$.

Therefore, glycemia is an important substrate for children submitted to cardiac surgery; however, its excess is a problem. A randomized clinical trial showed association of SSI in children submitted to cardiac surgery with hyperglycemia due to high glycemia levels possibly impairing the migration of neutrophils and macrophages to an infectious focus ${ }^{(24)}$. In face of such evidence, glycemic control in the first six hours from the immediate post-operative period for normal levels $(80-110 \mathrm{mg} / \mathrm{Dl})$ may reduce the probability of $\mathrm{SSI}^{(23-24)}$. This was thus one of the interventions which were chosen and legitimized by the judges for this bundle. The therapeutic measures for glycemia control are emphasized to be varied and decisions must be made on an individual basis ${ }^{(1)}$.

Item 6 alludes to the use of the prophylactic antibiotic in the postoperative period. Children submitted to cardiac surgery are more susceptible to various types of infections, including SSI, due to its systemic inflammatory response, a consequence of extracorporeal circulation, and present an immature immunological system, in addition to being 
exposed to multiple invasive procedures (thoracic tubes, central venous access, open thorax $)^{(25)}$. Therefore, the need for antimicrobial prophylaxis for these patients in the post-operative period, for at least 48 hours after surgery, has the objective of reducing the risk of infection and its efficacy is firmly proven among this population ${ }^{(25-27)}$. Thus, due to being a well-established intervention as an adjuvant factor in infection prevention, including SSI, the antimicrobial coverage in the postoperative period was designed and approved to integrate the bundle. In most cases the antimicrobial used as prophylaxis in the post-operative period is emphasized to be the same one used in the intraoperative period before the surgical incision (intervention 2) $)^{(25-27)}$.

Finally, item 7 emphasizes operative wound treatment and includes the maintenance of the bandage placed at the surgical center for 48 hours after the surgical procedure, emphasizing that, if the bandage has excessive exudate, it must be changed before the recommended time. The criterion for determining the time of permanence of the bandage is related to the wound healing process, as the inflammatory phase of wound healing generally occurs from two to three days after the procedure ${ }^{(28)}$. For this reason, maintaining the operative wound in sterile conditions, such as the bandage placed after surgery, avoids the contamination and proliferation of microorganisms, since bandages act as a physical barrier to protect the incision and absorb the wound exudate, maintaining it dry and clean and avoiding bacterial contamination of the surrounding area, in addition to providing ideal conditions for the process of wound healing ${ }^{(29)}$. It was selected for the bundle due to being a feasible intervention and contributing to the reduction of SSI rates.

As limitations of this study, a small number of studies with the best evidence levels, i.e., systematic reviews and meta-analysis of randomized clinical trials, level I, and randomized clinical trials, level II, was verified.

The use of all the interventions chosen for this bundle, through a grouped approach, is expected to contribute to the reduction of SSI rates among children submitted to cardiac surgery and thus improve care provided to this population.

\section{CONCLUSION}

The bundle, based on an integrative literature review, proposes care which is capable of preventing surgical site infections in children submitted to cardiac surgery, including actions implemented throughout the perioperative period, and includes the following interventions: preoperative bath with chlorhexidine, use of antibiotic one hour prior to the surgical incision, preparation of intraoperative skin with chlorhexidine antiseptic, change of surgical glove by surgeons after sternotomy and before sternum suture, hyperglycemia control, use of prophylactic antibiotic after surgery, and maintenance of the bandage placed at the surgical center for 48 hours after the surgical procedure. The bundle was validated by a group of 24 judges, obtaining a content validity index over 0.8 for all items referring to content and appearance, presenting statistical significance.

\section{RESUMO}

Objetivo: Construir e validar o conteúdo e a aparência de um bundle de prevenção de infecções de sítio cirúrgico em crianças submetidas à cirurgia cardíaca. Método: Estudo metodológico em duas etapas: 1) Construção do bundle a partir de uma revisão integrativa da literatura, na qual foram extraídas as intervenções para compor o instrumento; 2) Validação de conteúdo e aparência do bundle, com 24 juízes. Resultados: Foram encontrados 24 artigos que evidenciaram 17 intervenções para prevenção de infecção de sítio cirúrgico na referida população. Destas, sete propostas de intervenção foram elencadas para compor o bundle e enviadas para apreciação dos juízes. A proposta final incorpora todos os sete itens elencados na fase de construção, alcançando um índice de validade de conteúdo superior a 0,8 para todos os itens referentes ao conteúdo e aparência. Conclusão: $\mathrm{O}$ conteúdo e aparência do bundle desenvolvido propõe cuidados para prevenção de infecção de sítio cirúrgico em todo o período perioperatório.

\section{DESCRITORES}

Cirurgia Torácica; Criança; Infecção da Ferida Cirúrgica; Enfermagem Perioperatória; Estudos de Validação.

\section{RESUMEN}

Objetivo: Construir y validar el contenido y la apariencia de un bundle para la prevención de las infecciones de sitio quirúrgico en niños sometidos a cirugía cardiaca. Método: Estudio metodológico en dos etapas: 1) Construcción del bundle a través de una revisión integrativa de la literatura de la cual se extrajeron las intervenciones para componer el instrumento; 2) Validación de contenido y apariencia del bundle, con 24 jueces. Resultados: Se encontraron 24 artículos que evidenciaron 17 intervenciones para la prevención de la infección de sitio quirúrgico en esta población. De estas, siete propuestas de intervención fueron elegidas para componer el bundle y enviadas para la apreciación de los jueces. La propuesta final incorpora todos los siete ítems elegidos en la etapa de construcción, llegando a un índice de validez de contenido superior a 0.8 para todos los ítems referentes al contenido y a la apariencia. Conclusión: El contenido y apariencia del bundle desarrollado propone cuidados para la prevención de la infección de sitio quirúrgico en todo el período perioperatorio.

\section{DESCRIPTORES}

Cirugía Torácica; Niño; Infección de la Herida Quirúrgica; Enfermería Perioperatoria; Estudio de Validación.

\section{REFERENCES}

1. Brasil. Ministério da Saúde; Agência Nacional de Vigilância Sanitária. Medidas de prevenção de infecção relacionada à assistência à saúde. Brasília: ANVISA; 2017.

2. Sochet AA, Cartron AM, Nyhan A, Song X, Brown AT, Klugman D. Surgical site infection after pediatric cardiothoracic surgery: impact on hospital cost and length of stay. World J Pediatr Congenit Heart Surg. 2017;8(1):7-12. https://doi.org/10.1177/2150135116674467

3. Tweddell S, Loomba RS, Cooper DS, Benscoter AL. Health care associated infections are associated with increased length of stay and cost but not mortality in children undergoing cardiac surgery. Congenit Heart Dis. 2019:14(5):785-790. https://doi.org/10.1111/chd.12779 
4. Gonzalez DO, Ambeba E, Minneci PC, Deans KJ, Nwomeh DC. Surgical site infection after stoma closure in children: outcomes and predictors. J Surg Res. 2017;209:234-41. https://doi.org/10.1016/j.jss.2016.10.029

5. Izquierdo-Blasco J, Campins-Martí M, Soler-Palacín P, Balcells J, Abella R, Gran F, et al. Impact of the implementation of an interdisciplinary infection control program to prevent surgical wound infection in pediatric heart surgery. Eur J Pediatr. 2015;174(7):957-63. https://doi.org/10.1007/s00431-015-2493-9

6. Cannon M, Hersey D, Harrison S, Joy B, Naguib A, Galantowicz M, et al. Improving Surveillance and Prevention of Surgical Site Infection in Pediatric Cardiac Surgery. Am J Crit Care. 2016;25(2):e30-7. https://doi.org/10.4037/ajcc2016531.

7. Woodward C, Taylor R, Son M, Taeed R, Jacobs ML, Kane L, et al. Multicenter quality improvement project to prevent sternal wound infections in pediatric cardiac surgery patients. World J Pediatr Congenit Heart Surg. 2017:8(4):453-9. https://doi.org/10.1177/2150135117713741

8. Silva MPC, Bragato AGC, Ferreira DO, Zago LB, Toffano SEM, Nicolussi AC, et al. Bundle para manuseio do cateter central de inserção periférica em neonatos. Acta Paul Enferm. 2019;32(3):261-6. https://doi.org/10.1590/1982-0194201900036

9. Bertoglio S, Van Boxtel T, Goossens GA, Dougherty L, Furtwangler R, Lennan E, et al. Improving outcomes of short peripheral vascular access in oncology and chemotherapy administration. J Vasc Access. 2017;18(2):89-96. https://doi.org/10.5301/jva.5000668.

10. Zegers M, Hesselink G, Geense W, Vincent C, Wollersheim H. Evidence-based interventions to reduce adverse events in hospitals: a systematic review of systematic reviews. BMJ Open. 2016;6(9):e012555. http://dx.doi.org/10.1136/bmjopen-2016-012555

11. Wang W, Zhao C, Ji Q, Liu Y, Shen G, Wei L. Prevention of peripherally inserted central line-associated blood stream infections in very low-birth-weight infants by using a central line bundle guideline with a standard checklist: a case control study. BMC Pediatr. 2015;15:69. https://doi.org/10.1186/s12887-015-0383-y.

12. Krempser P, Arreguy-Sena C, Parreira PMDSD, Salgueiro-Oliveira AS. Nursing protocol in vascular trauma prevention: peripheral catheterization bundle in urgency. Rev Bras Enferm. 2019;72(6):1512-8. http://dx.doi.org/10.1590/0034-7167-2018-0457

13. Lapa-Rodriguez EO, Oliveira JKA, Melo FC, Silva GV, Mattos MCT, Macieira Junior VP. Insertion of central vascular catheter: adherence to infection prevention bundle. Rev Bras Enferm. 2019; 72(3):774-9. http://dx.doi.org/10.1590/0034-7167-2018-0124

14. Chan A-W, Tetzlaff JM, Altman DG, Laupacis A, Gøtzsche PC, Krleža-Jerić K, et al. SPIRIT 2013 Statement: defining standard protocol items for clinical trials. Ann Intern Med. 2013;158(3):200-7. https://doi.org/10.7326/0003-4819-158-3-201302050-00583

15. Rubio DM, Ber-Weger M, Tebb SS, Lee S, Rauch S. Objectifying content validity: conducting a content validity study in social work research. Soc Work Res. 2003;27(2):94-11. https://doi.org/10.1093/swr/27.2.94.

16. Oliveira LL, Mendes IC, Balsells MMD, Bernado EBR, Castro RCMB, Aquino OS, et al. Educational hypermedia in nursing assistance at birth: building and validation of content and appearance. Rev Bras Enferm. 2019;72(6):1471-8. https://doi.org/10.1590/0034-7167/20180163

17. Delgado-Corcoran C, Van Dorn CS, Pribble C, Thorell EA, Pavia AT, Ward C, et al. Reducing pediatric sternal wound infections: a quality improvement project. Pediatr Crit Care Med. 2017;18(5):461-8. https://doi.org/10.1097/PCC.0000000000001135

18. Álvarez CA, Guevara CE, Valderrama SL, Sefair CF, Cortes JA, Jimenez MF, et al. Practical recommendations for preoperative skin antisepsis. Infectio. 2018;22(1):46-54. https://doi.org/10.22354/in.v0i0.704

19. Park HM, Han SS, Lee EC, Yoon HM, Eom BW, Kim SH, et al. Randomized clinical trial of preoperative skin antisepsis with chlorhexidine gluconate or povidone-iodine. Br J Surg. 2017;104(2):e145-50. https://doi.org/10.1002/bjs.10395

20. Shah GS, Christensen RE, Wagner DS, Pearce BK, Sweeney J, Tait AR. Retrospective evaluation of antimicrobial prophylaxis in prevention of surgical site infection in the pediatric population. Paediatr Anaesth. 2014;24(9):994-8. https://doi.org/10.1111/pan.12436

21. Toltzis P, O'Riordan M, Cunningham DJ, Ryckman FC, Bracke TM, Olivea J, et al. A statewide collaborative to reduce pediatric surgical site infections. Pediatrics. 2014;134(4):e1174-80. https://doi.org/10.1542/peds.2014-0097

22. Oliveira AC, Gama GS, França PR. Qual o intervalo de tempo sugerido para a troca de luvas cirúrgicas? Uma revisão integrativa. Rev Eletr Enf. 2016;18:1-16. https://doi.org/10.5216/ree.v18.37036

23. Agus MS, Wypij D, Hirshberg EL, Srinivasan V, Faustino V, Luckett PM, et al. Tight glycemic control in critically ill children. N Engl J Med. 2017;376(8):729-41. https://doi.org/10.1056/NEJMoa1612348.

24. Agus MS, Asaro LA, Steil GM, Alexander JL, Silverman M, Wypij D, et al. Tight glycemic control after pediatric cardiac surgery in high-risk patient populations: a secondary analysis of the safe pediatric euglycemia after cardiac surgery trial. Circulation. 2014;129(22):2297304. https://doi.org/10.1161/CIRCULATIONAHA.113.008124

25. Philip J, Kegg C, Lopez-Colon D, Kelly BJ, Lawrence RM, Robinson MA, et al. Safety of a 2-day antibiotic regimen after delayed chest closure post pediatric cardiac surgery. J Intensive Care Med. 2020;35(8):805-9. https://doi.org/10.1177/0885066618792849

26. Bath S, Lines J, Loeffler AM, Malhotra A, Turner RB. Impact of standardization of antimicrobial prophylaxis duration in pediatric cardiac surgery. J Thorac Cardiovasc Surg. 2016;152(4):1115-20. https://doi.org/10.1016/j.jtcvs.2016.04.091

27. Hatachi T, Sofue T, Ito Y, Inata Y, Shimizu Y, Hasegawa M, et al. Antibiotic prophylaxis for open chest management after pediatric cardiac surgery. Pediatr Crit Care Med. 2019;20(9):801-8. https://doi.org/10.1097/PCC.0000000000001995

28. Childs DR, Murthy AS. Overview of wound healing and management. Surg Clin North Am. 2017;97(1):189-207. https://doi.org/10.1016/ j.suc.2016.08.013

29. Vieira ALG, Stocco JGD, Ribeiro ACG, Frantz CV. Dressings used to prevent surgical site infection in the postoperative period of cardiac surgery: integrative review. Rev Esc Enferm USP. 2018;52:e03393. https://doi.org/10.1590/s1980-220x2017011803393 